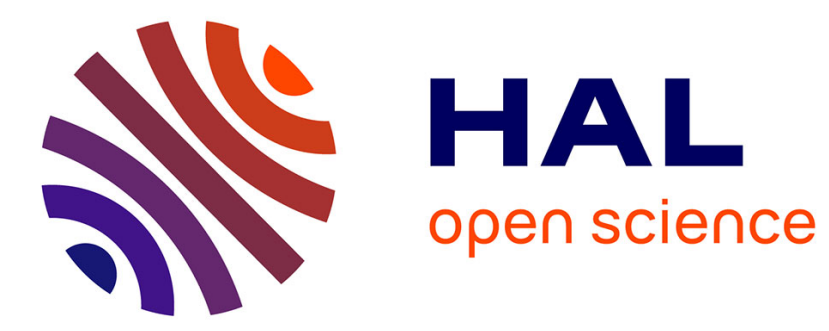

\title{
Parameters Identification and Gas Behavior Characterization of DBD Systems
}

Andres Mauricio Lopez, Hubert Piquet, Diego Patino, Rafael Diez, Xavier Bonnin

\section{- To cite this version:}

Andres Mauricio Lopez, Hubert Piquet, Diego Patino, Rafael Diez, Xavier Bonnin. Parameters Identification and Gas Behavior Characterization of DBD Systems. IEEE Transactions on Plasma Science, 2013, vol. 41 ( $\mathrm{n}^{\circ}$ 8), pp. 2335-2342. 10.1109/TPS.2013.2273462 . hal-01425294

\section{HAL Id: hal-01425294 \\ https://hal.science/hal-01425294}

Submitted on 3 Jan 2017

HAL is a multi-disciplinary open access archive for the deposit and dissemination of scientific research documents, whether they are published or not. The documents may come from teaching and research institutions in France or abroad, or from public or private research centers.
L'archive ouverte pluridisciplinaire HAL, est destinée au dépôt et à la diffusion de documents scientifiques de niveau recherche, publiés ou non, émanant des établissements d'enseignement et de recherche français ou étrangers, des laboratoires publics ou privés. 


\section{OATAO}

\section{Open Archive Toulouse Archive Ouverte (OATAO)}

OATAO is an open access repository that collects the work of Toulouse researchers and makes it freely available over the web where possible.

This is an author-deposited version published in: http://oatao.univ-toulouse.fr/ Eprints ID: 17320

To link to this article : DOI: 10.1109/TPS.2013.2273462

URL : http://dx.doi.org/10.1109/TPS.2013.2273462

To cite this version: Lopez, Andres Mauricio and Piquet, Hubert and Patino, Diego and Diez Medina, Rafael and Bonnin, Xavier Parameters Identification and Gas Behavior Characterization of DBD Systems. (2013) IEEE Transactions on Plasma Science, vol. 41 (n 8). pp. 2335-2342. ISSN 0093-3813

Any correspondence concerning this service should be sent to the repository administrator: staff-oatao@listes-diff.inp-toulouse.fr 


\section{Parameters Identification and Gas Behavior Characterization of DBD Systems}

Andres Mauricio Lopez, Student Member, IEEE, Hubert Piquet, Diego Patino, Member, IEEE, Rafael Diez, Member, IEEE, and Xavier Bonnin

\begin{abstract}
This paper proposes an efficient modeling and an identification method for dielectric barrier discharge (DBD) systems, based on input-output (current-voltage) experimental measurements. The DBD is modeled using an equivalent electric circuit associated with a differential equation that describes the dynamics of its conductance. This equation assumes a homogeneous behavior of the gas. This paper introduces a series of polynomial terms of the current of the gas into the conductance equation. These terms, after identification, are a very useful tool to analyze the physical mechanisms that take place in the gas. The identification process also returns the numerical values of other DBD parameters, such as associated capacitances and the breakdown voltage. In addition, an asymmetric model for the gas, which considers the direction of the current, is proposed to consider the possible geometrical dissimilarity between the two electrodes of the DBD setup. Experimental measurements taken on two different DBD applications are used for validating the proposed approach.
\end{abstract}

Index Terms-Dielectric barrier discharge (DBD), gas conductance, gray box, modeling, parameter identification.

\section{INTRODUCTION}

D IELECTRIC barrier discharges (DBDs) offer specific properties that are very interesting for a large number of processes. The obtained plasma is maintained at low temperatures, the barriers contribute to spread the discharge on the whole surface of the electrodes and they avoid direct contact between the metallic electrodes and the gas. Thus, it increases lifetimes and reduces costs. For these reasons, DBD are widely used in industrial applications such as ozone generators, surface treatments, thin film deposits and coating, lighting, and displays [1]-[3].

Barriers used in DBD setups are made of dielectric materials (ceramics, glass for instance), which forbid the use of a DC power supply to inject power into the system. Therefore, the electric power source must be especially designed for

A. M. Lopez is with Pontificia Universidad Javeriana, Bogota 1100100 Colombia (e-mail: lopez.andres@javeriana.edu.co).

H. Piquet and X. Bonnin are with the LAPLACE laboratory, Toulouse 31071, France (e-mail: hubert.piquet@laplace.univ-tlse.fr; bonnin@ laplace.univ-tlse.fr).

R. Diez and D. Patino are with the Department of Electronics, Pontificia Universidad Javeriana, Bogota 12345, Colombia (e-mail: rdiez@ javeriana.edu.co; patino-d@ javeriana.edu.co).

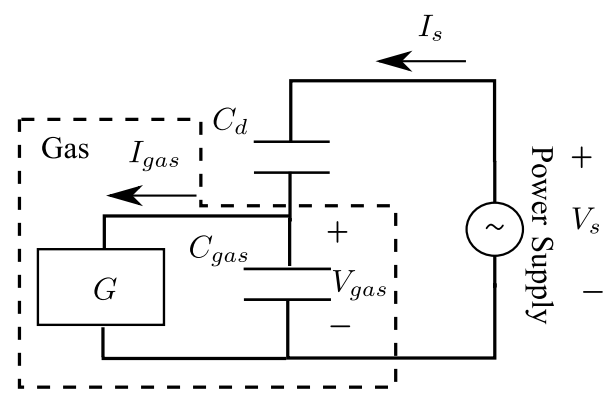

Fig. 1. Detailed electrical model of a DBD. $V_{S}$ and $I_{S}$ represent the generator voltage and current, $C_{\text {gas }}$ and $C_{d}$ the capacitance of the gas and the equivalent capacitance of the dielectric, $V_{\text {gas }}$ and $I_{\text {gas }}$ the voltage and current of the gas, and $G$ the conductance of the gas.

each DBD process if precise operating points and effective control of the power transfers are desired. To make this possible, an electric model of the DBD, relating the current and voltage at the electrodes, is very useful to correctly dimension the components of the power converters at the design stage.

In this scope, the availability of such a model permits the achievement of numerical simulations (with software such as PSIM or PSPICE) associating the circuit of the electrical generator to the DBD system which has to supply. These simulations, as described in [4], allow the prediction of the operating conditions for the whole system. It also gives the possibility to know the power that is transferred to the gas and therefore, to the process in the plasma. In addition, the waveforms and magnitudes of the electrical variables of the electronic components in the power supply can be known as well.

The current-voltage relationship that describes the behavior of the DBD device can be found, using experimental waveforms with various approaches. Among them, the black-box technique is able to define an accurate model of the system. Nevertheless, it is meaningless from the physics and electrical point of view [5]-[7]. On the other hand, the electrical or circuit-based model, displays a capacitance for the dielectrics, a capacitance for the gas, and a conductance for the gas. This model gives more insight into the physics and eases the implementation in simulation software for electric circuits. In this paper, the second approach is used; a nonlinear differential equation to model the dynamics of the gas conductance is proposed. Therefore, nonlinear identification method is used to determine the parameters of this model.

The equivalent circuit of the DBD used in this paper is derived from the well-known model mentioned in [8] 


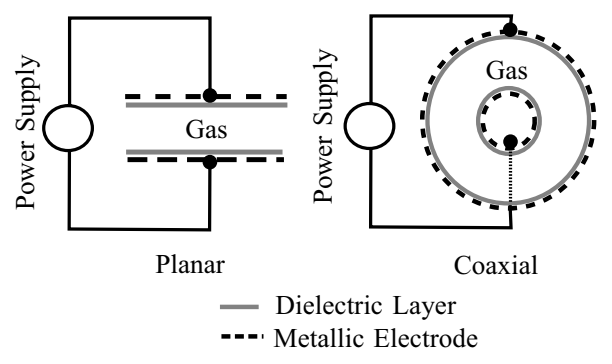

Fig. 2. Physical structures of the considered DBD setups.

(see Fig. 1). This model includes the capacitances of the dielectric barriers, the capacitance of the gas gap, and the conductance of the gas.

One of the most relevant contributions of this paper is obtained because of the introduction of polynomial series terms of the gas current into the equation governing the evolution of the conductance. These terms provide crucial information concerning the behavior of the discharge in the gas gap. They may vary depending on the operating condition, which are not always a priori known. Those terms also help in making the balance between the most significant phenomena, which can take place in the plasma, e.g. thermal influence, ionization, breakdown, and recombination of the excited species [9], [10].

The proposed approach is tested on two completely different DBD applications: 1) an experimental reduced scale setup for plastic film surface treatments and 2) a $90 \mathrm{~W}$ excimer UV lamp. The first application is a coplanar DBD in nitrogen at atmospheric pressure, oriented to film-coating, as shown in Fig. 2 (left). Both the electrodes are covered with a ceramic layer, acting as dielectric barrier. The second application concerns excimer lamps, which are high performance UV radiation generators [11]-[14]. This UV is produced, in the gas mixture contained in the lamp during the decay of excited molecules returning to their ground state after an electric excitation. In the selected bulb, the DBD is produced in a $\mathrm{Kr}-\mathrm{Cl}$ gas mixture at low pressure. Hence, the setup presents an asymmetric configuration because the outer electrode is larger than the inner electrode [see Fig. 2 (right)], with different radius of curvature and thus different local electric fields.

Considering this geometry, this paper also deals with the possible dissimilarities between the electrodes on a DBD setup. Expecting that DBD setups with different sizes or shapes of electrodes, can exhibit a specific behavior of the gas depending on the current direction.

This paper is organized as follows: Section II enounces the electrical model of the DBD and its mathematical representation of the gas behavior for the symmetrical and asymmetrical cases. Section III presents the identification technique. Finally Section IV validates the model and the identification method for the two proposed applications, with a detailed analysis of the terms in the conductance equation.

\section{DBD Electrical Model}

A well-known equivalent circuit of the DBD setup consist of one or two dielectric barriers and a gas volume as shown in Fig. $1\left(C_{d}\right.$ represents the equivalent series capacitance of

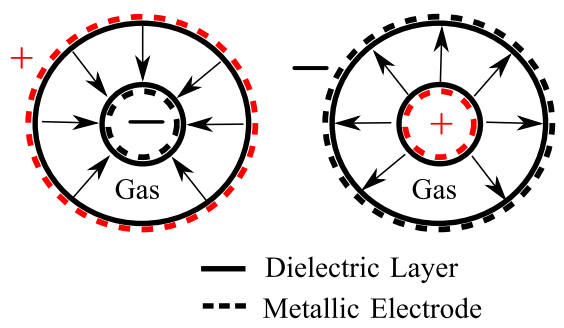

Fig. 3. Lateral view of the lamp with current directions.

the dielectric barriers). $C_{\text {gas }}$ is the capacitance of the gas when no electric discharge takes place in the latter. $G$ is the conductance of the gas when a plasma is installed. One of the main assumption and limitation of this modeling approach is that a homogeneous behavior of the gas is assumed.

Parameters such as the capacitances of the dielectrics, capacitance of the gas, and constants related to the gas are needed to implement the equivalent model in a circuit simulator. Therefore, they have to be estimated on the basis of the measurable variables. In an experimental setup, the only measurable variables are the current through the DBD $I_{s}$ and its voltage $V_{s}$.

The structure of this equivalent model of the DBD is similar to the one proposed in [8]. According to the circuit of Fig. 1, the system is described by the following differential state equations:

$$
\begin{aligned}
\frac{d V_{\mathrm{gas}}}{d t} & =\frac{I_{s}-V_{\mathrm{gas}} G}{C_{\mathrm{gas}}} \\
\frac{d V_{C_{d}}}{d t} & =\frac{I_{s}}{C_{d}} .
\end{aligned}
$$

The voltage of the DBD setup is easily computed as follows:

$$
V_{s}=V_{C_{d}}+V_{\mathrm{gas}} .
$$

\section{A. Symmetrical Model}

For the case of a symmetrical DBD setup such as a plastic films surface treatment reactor, the equation of the conductance $G$ is proposed to be defined with several aspects of the behavior of the electric discharge. Polynomial terms of the current of the gas are added as follows:

$$
\frac{d G}{d t}=K_{1} u\left(V_{t h}-\left|V_{\text {gas }}\right|\right)-K_{2} G+\sum_{n=1}^{\infty} T_{n}\left|I_{\text {gas }}\right|^{n}
$$

where the function |.| is the absolute value of the argument and $u($.$) the Heaviside function and V_{t h}$ is the breakdown voltage of the gas. It can be observed that:

1) the first term represents the ionization process at the breakdown and $K_{1}$ is a generation coefficient;

2) the second term represents the recombination process after breakdown and $K_{2}$ is the extinction coefficient;

3) In the last term, $T_{n}$ coefficients reflect the relationship between the conductance and different powers of the conduction current into the gas $I_{\text {gas }}$. The relative importance of these terms reflects the properties of the gas and the physical phenomena that take place in the latter. 

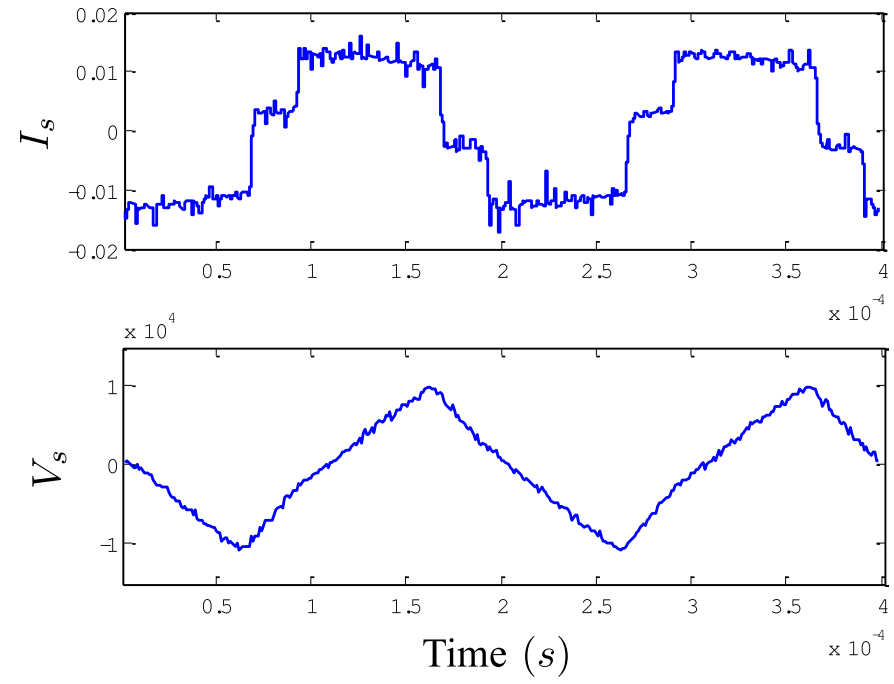

Fig. 4. Measured current (input) and voltage (output) of the DBD for film treatment.

TABLE I

CHARACTERISTICS OF THE DBD FOR FILM TREATMENT

\begin{tabular}{|l|c|}
\hline Surface & $9 \mathrm{~cm}^{2}$ \\
$\epsilon_{r}$ & 7 \\
Gap & $1 \mathrm{~mm}$ \\
Dielectric thickness & $1.2 \mathrm{~mm}$ \\
$C_{d}$ & $46 p F$ \\
$C_{\text {gas }}$ & $8 p F$ \\
$V_{\text {th }}$ & $3500 \mathrm{~V}$ \\
\hline
\end{tabular}

\section{B. Asymmetric Model}

Some DBD systems, such as DBD lamps have an asymmetric structure, with two coaxial cylinders. Therefore, the inner and outer electrodes also have different radii. Depending on the direction of the current of the lamp, the radius of the anode is bigger or smaller than the radius of the cathode (see Fig. 3) and the magnitude of the local electrical field in the neighborhood of the cathode is modified.

To consider this asymmetry in the mathematical model and to improve the identification results, the equation of the conductance of the gas is proposed to be modified as follows:

$$
\begin{aligned}
& \frac{d G}{d t} \\
& = \begin{cases}K_{1} u\left(V_{t h}-\left|V_{\text {gas }}\right|\right)-K_{2} G+\sum_{n=1}^{\infty} T_{n} I_{\text {gas }}^{n}, & \text { if } I_{\text {gas }} \geq 0 \\
K_{1}^{\dagger} u\left(V_{t h}^{\dagger}-\left|V_{\text {gas }}\right|\right)-K_{2}^{\dagger} G+\sum_{n=1}^{\infty} T_{n}^{\dagger}\left(-I_{\text {gas }}\right)^{n}, & \text { if } I_{\text {gas }}<0 .\end{cases}
\end{aligned}
$$

Different parameters are used for each direction of the current. The values of the dielectric capacitance $C_{d}$ in (1) and the gas capacitance $C_{\mathrm{gas}}$ in (2) are assumed to be independent on the current direction.

\section{IdentificAtion of THE Model Parameters}

To obtain the electrical and physical constants of the DBD system, a gray-box identification technique is considered. This method maintains the physical and electrical meaning for the
TABLE II

Numerical Results of the Parameters of the DBD for Film TREATMENT UP TO $T_{10}$

\begin{tabular}{|l|c|}
\hline \multicolumn{2}{|c|}{ Parameters } \\
\hline$C_{d}$ & $69.3 p F$ \\
$C_{\text {gas }}$ & $10.5 p F$ \\
$V_{t h}$ & $3870 \mathrm{~V}$ \\
$K_{1}$ & 150.2 \\
$K_{2}$ & 636 \\
$T_{1}$ & 85.2 \\
$T_{2}$ & 270.2 \\
$T_{3}$ & 1.11 \\
$T_{4}$ & 6.143 \\
$T_{5}$ & 6.248 \\
$T_{6}$ & 6.249 \\
$T_{7}$ & 6.25 \\
$T_{8}$ & 6.25 \\
$T_{9}$ & 6.25 \\
$T_{10}$ & 6.25 \\
\hline
\end{tabular}

identified parameters. It requires previous knowledge of the dynamical system behavior.

\section{A. Gray-Box Identification Algorithm}

As seen in Section II, the system is modeled as a set of differential equations with a set of unknown parameters $p$ to be identified, as follows:

$$
\dot{x}=f(x, p, u), \quad y=h(x, p, u)
$$

where $x$ is the state space vector, $p$ is the vector of unknown parameters to be identified, $u$ the inputs and $y$ the outputs. For this case $u=I_{s}$ and $y=V_{s}$. The functions $f(x, p, u)$ and $h(x, p, u)$ are known: $f$ is described in (1)-(4) and $h$ is computed according to (3). The inputs $u$ and outputs $y$ are measurable and known.

The objective of the identification process is to minimize the norm of the quadratic error, varying the parameters $p$ as follows:

$$
\min _{p}\left(\|e(p)\|^{2}\right)=\min _{p}\left(\|y-\hat{y}\|^{2}\right)
$$

where $\|*\|^{2}$ is the square of the norm of the argument, $e(p)$ is the error between $\hat{y}$ the measured output and $y$ the estimated one. In a general case, the error is a nonlinear function of $p$ [15], [16].

The algorithm approximates the error function around $p_{0}$ (initial condition of the vector $p$ ) with a simpler quadratic function, then the minimization problem (7) is reduced to the following:

$$
\min _{s}\left\{\frac{1}{2} s^{T} H s+s^{T} g,\|s\|<\Delta\right\} .
$$

A trial step $s$ is computed to try to minimize the quadratic approximation of the error in (8). Then, it is verified if $e(p)$ is reduced. In this case, the parameter $p_{0}$ is updated as $p_{0}^{\text {new }}=$ 


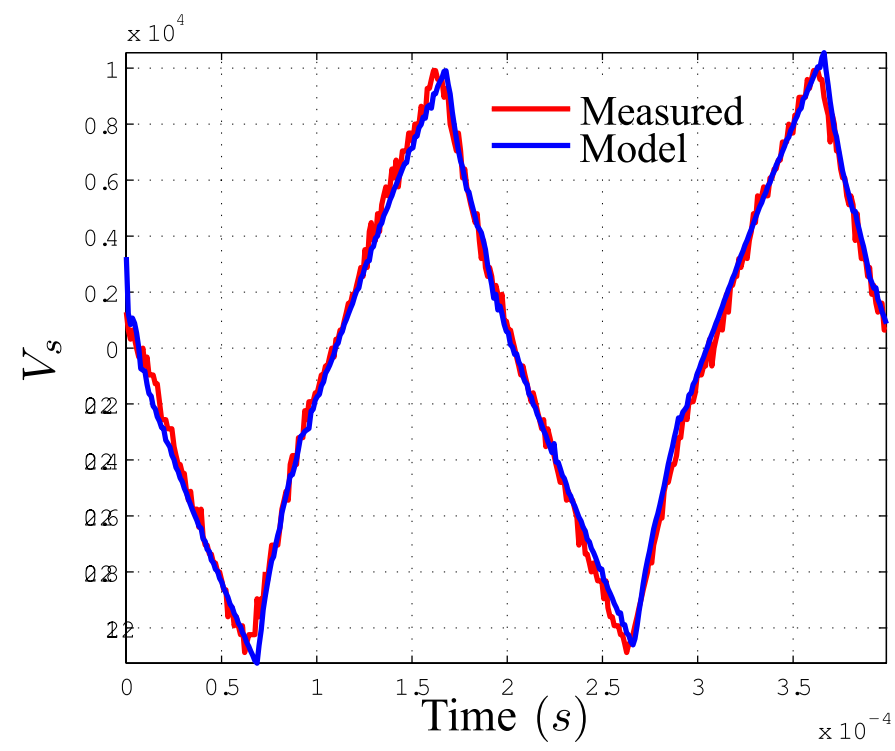

Fig. 5. Response of the identified model (FIT $=90.5 \%)$ to the identification waveform.

$p_{0}+s$ if $e\left(p_{0}+s\right)<e\left(p_{0}\right)$. Otherwise, the parameter $\Delta$ is reduced [17].

This algorithm is also capable to deal with constrains in the parameters $p$ (see [17] and [18] for further information).

\section{B. Summary of DBD Setup Identification Problem}

For the DBD system, the set of nonlinear differential equations (6) is defined in (1)-(4).

The components of the state space vector $x$ are $V_{d}, V_{\mathrm{gas}}$, and $G$. The input variable $u$ is the DBD current $I_{s}$ and the output $y$ is the DBD voltage $V_{s}$.

The set of parameters to be identified are $p=\left[C_{d}, C_{\mathrm{gas}}\right.$, $V_{t h}, K_{1}, K_{2}, T_{n}$ with $\left.n=1,2,3 \ldots, \infty\right]$.

\section{IDENTIFICATION RESULTS}

The identification method is used for two different DBD systems, considered in this section: a DBD for film treatment with a planar structure and a DBD UV lamp with a coaxial structure (see Fig. 2).

\section{A. DBD for Film Treatment}

Fig. 4 shows the measured waveforms used for the identification, current $I_{s}$ and voltage $V_{s}$ in the DBD system. The specific shape of the current has been obtained with an especially designed current-controlled power supply [19].

Initial guess of parameters set is deduced from the characteristics of the DBD shown in Table I.

1) Identification Results: The algorithm needs 90 iterations to converge. Table II shows the obtained parameters.

Fig. 5 shows a comparison of the actual response of the $\operatorname{DBD}\left(V_{s}\right.$ voltage $)$ and the response obtained with the identified model. The FIT index is used to measure the quality of the identified model. It is calculated as follows:

$$
\mathrm{FIT}=100\left(1-\frac{\|\hat{y}-y\|}{\|y-\hat{\hat{y}}\|}\right) \%
$$

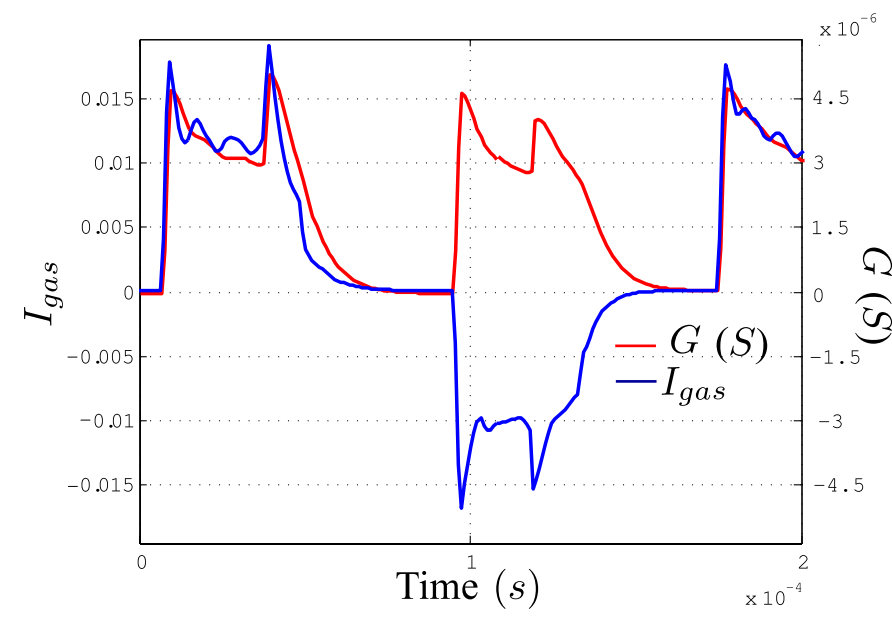

Fig. 6. Estimated current $I_{\text {gas }}$ and conductance $G$ of a DBD system for film treatment.

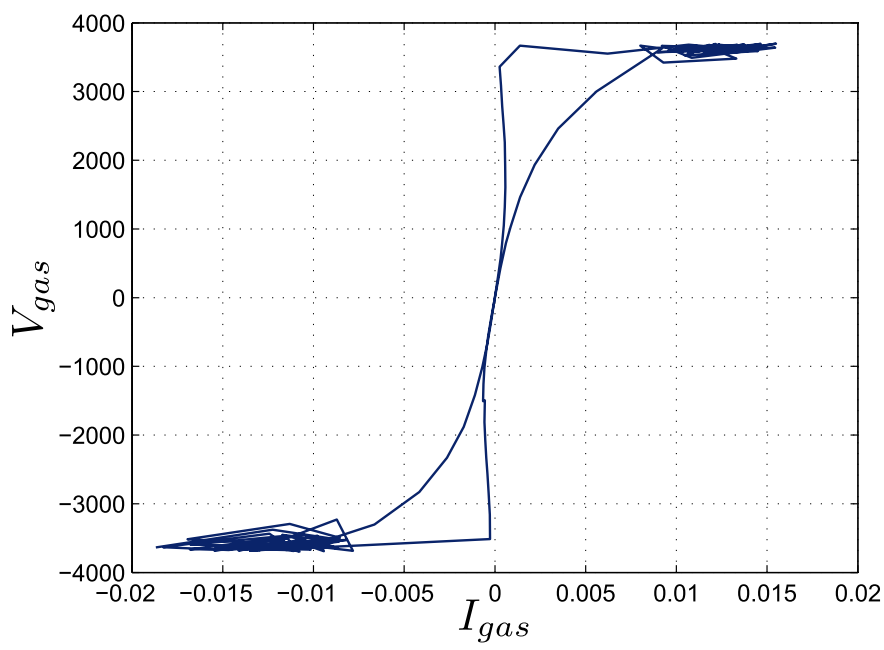

Fig. 7. Behavior of the gas ( $I_{\text {gas }}$ versus $V_{\text {gas }}$ ) of a DBD system for film treatment.

where $\|*\|$ is the norm of the argument, $y$ the results obtained with the theoretical model, $\hat{y}$ the experimental measurements, and $\overline{\hat{y}}$ the average of the vector $\hat{y}$. The model clearly reflects the behavior of the system for the identification data with FIT $=90.5 \%$.

One of the advantages of the equivalent circuit approach is the possibility to estimate electrical variables such as the current in the gas $I_{\text {gas }}$ or the conductance $G$ (Fig. 6). It is possible to see that the value of the gas conductance $G$ is stable as long as the current flows through the gas.

Fig. 7 shows the behavior of the gas current $I_{\text {gas }}$ versus the gas voltage $V_{\text {gas }}$. When the gas is ignited, its voltage remains almost constant for different values of current, suggesting a normal glow operating regime.

2) Comparison of Polynomial Terms: To simplify the identified model, the relative importance of each polynomial term (i.e, $T_{n}\left|I_{\text {gas }}\right|^{n}$ ) is analyzed. Fig. 8 shows a comparison of the polynomial terms for the film treatment DBD setup. For the comparison, the RMS which represents the average power of 


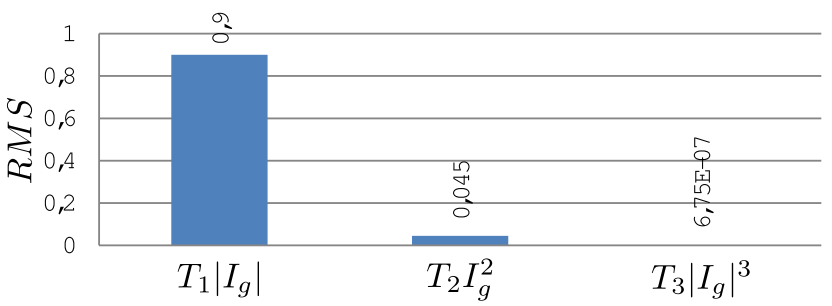

Fig. 8. Comparison of RMS value of the polynomial terms of the current of the gas $I_{\text {gas }}$ for the identification waveforms. RMS values of terms with fourth power and greater are in magnitude order $\times 10^{-9}$ and are not shown.
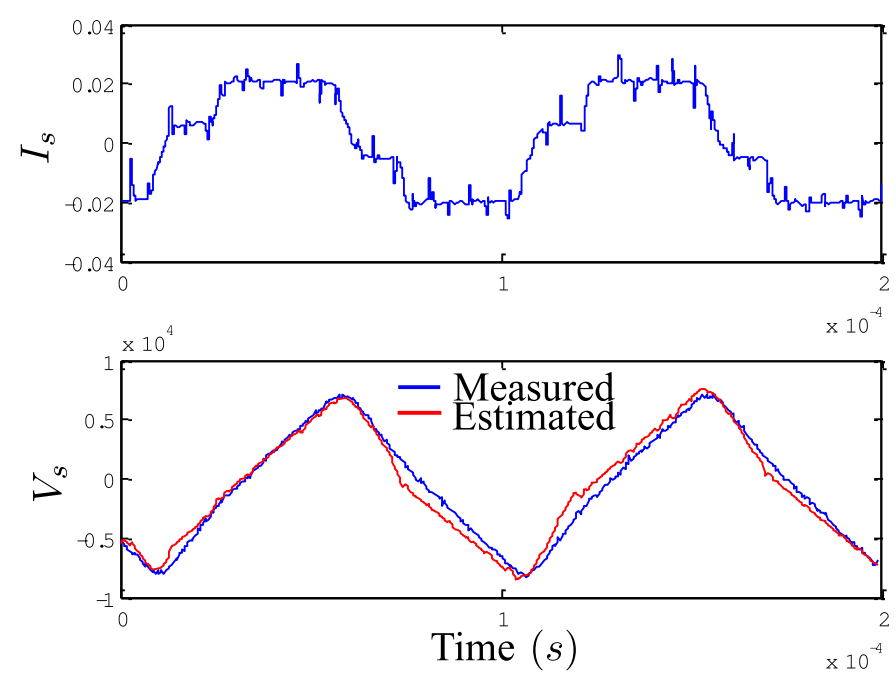

Fig. 9. Measured current $I_{S}$ and measured and estimated voltage $V_{S}$ of the DBD for film treatment FIT $=81.1 \%$.

the waveform is used. It is computed as follows:

$$
\left\|T_{n}\left|I_{\mathrm{gas}}\right|^{n}\right\|_{\mathrm{RMS}}=\sqrt{\frac{1}{T} \int_{0}^{T}\left(T_{n}\left|I_{\mathrm{gas}}(\tau)\right|^{n}\right)^{2} d \tau}
$$

where $T$ is an integer multiple of the operation period. For this DBD the most important term is $T_{1}\left|I_{\text {gas }}\right|$. The RMS of this term is more than 10 times greater than for $T_{2}\left|I_{\text {gas }}\right|^{2}$. Fig. 8 confirms that the gas conductances can be sustained by means of the gas current. For instance, let us consider only the first term of the polynomial powers in the gas current $T_{1}\left|I_{g}\right|$ as important. If a slowly varying current is applied during certain time after breakdown, (4) states that the conductance is proportional to the absolute value of the current amplitude in steady state (as seen in Fig. 6). This confirms the normal glow regime.

3) Predictability of the Model: The identified model is validated with five other waveforms, with different frequencies and amplitudes, obtaining an average FIT of $85.3 \%$. Fig. 9 shows the waveform (measured and estimated) with the worst FIT.

\section{B. DBD Lamp}

The identification algorithm is used for the characterization of a DBD $\mathrm{Kr}-\mathrm{Cl}$ excimer UV lamp. The waveforms of the measured current $I_{S}$ (input) and voltage of the lamp $V_{S}$ (output) are shown in Fig. 10. These figures are obtained with a specifically designed power supply, designed for the research of the
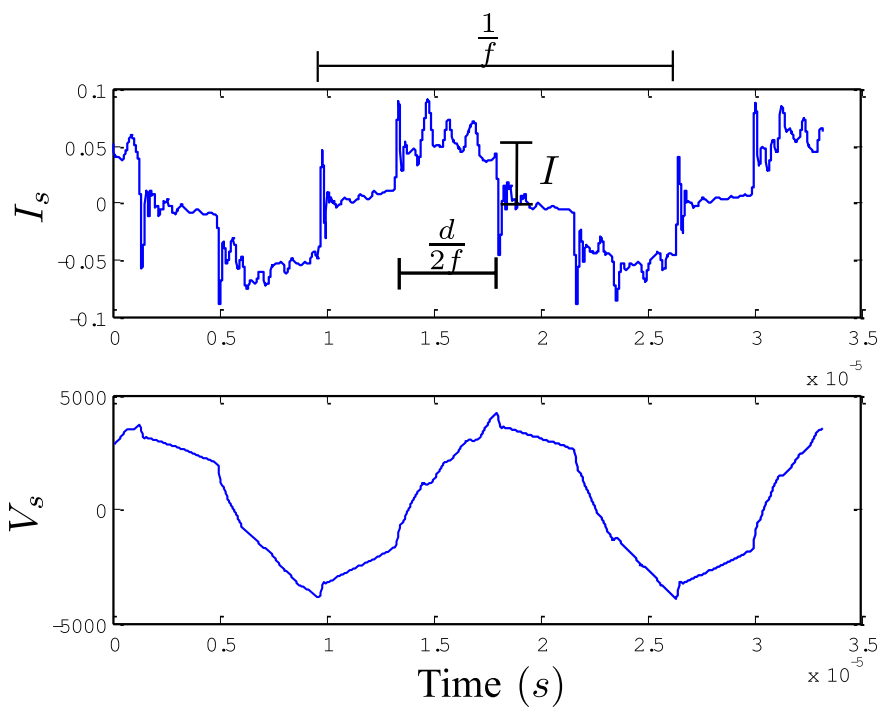

Fig. 10. Measurements of the DBD lamp current $I_{S}$ (input) and voltage $V_{S}$ (output) used for identification.

TABLE III

NumericAl RESUlts of THE PARAMETERs OF THE IDENTIFIED MODELS FOR THE DBD LAMP UP TO $T_{10}$

\begin{tabular}{|l|c|}
\hline \multicolumn{2}{|c|}{ Parameters } \\
\hline$C_{d}$ & $56.1 p F$ \\
$C_{g a s}$ & $22.4 p F$ \\
$V_{t h}$ & 1998.8 \\
$K_{1}$ & 250.4 \\
$K_{2}$ & 21408.2 \\
$T_{1}$ & 503 \\
$T_{2}$ & 3205 \\
$T_{3}$ & 1.45 \\
$T_{4}$ & 9.12 \\
$T_{5}$ & 20.29 \\
$T_{6}$ & 24.33 \\
$T_{7}$ & 24.93 \\
$T_{8}$ & 24.99 \\
$T_{9}$ & 24.99 \\
$T_{10}$ & 24.99 \\
\hline
\end{tabular}

optimal operating conditions of the lamp [20]. This power supply is capable of changing the frequency $f$, amplitude $I$, and duty cycle $d$ of the current waveform (see Fig. 10).

1) Identification Results (Symmetrical Model): To compare the results obtained with symmetrical and asymmetrical model in the DBD lamp, the identification algorithm is run at first for the symmetrical case. The identification algorithm converges in 80 iterations. Table III shows the numerical results of the parameters of the model.

Fig. 11 shows a comparison between the measured DBD lamp voltage and the response obtained with the identified model. The FIT index is used to measure the quality of the identified model as in the case of the DBD for film treatment. The model clearly reflects the behavior of the DBD lamp for the identification data with FIT $=91.7 \%$. 


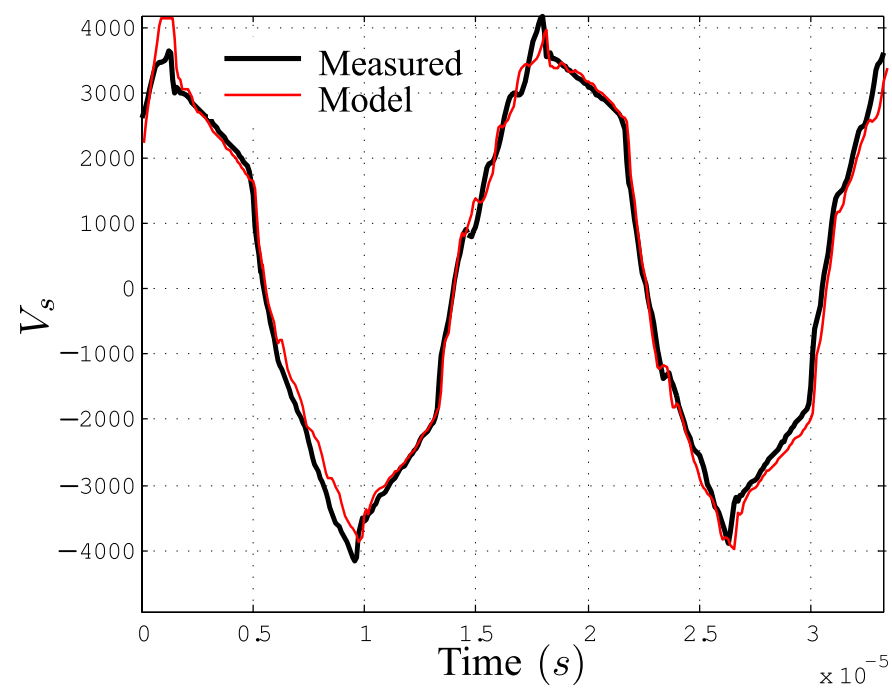

Fig. 11. Response of the identified models (FIT $=91.7 \%$ ) to the identification waveform.

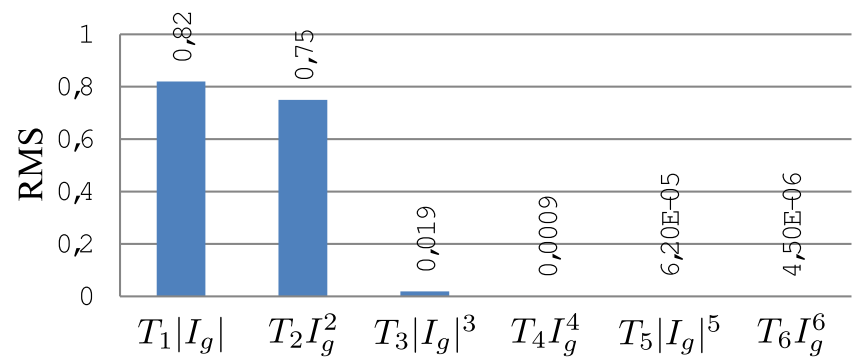

Fig. 12. Comparison of RMS value of the polynomial terms of the current of the gas $I_{\text {gas }}$ for the identification waveforms using the polynomial model. RMS values of terms with seventh power and greater are in magnitude order $\times 10^{-9}$ and are not shown.
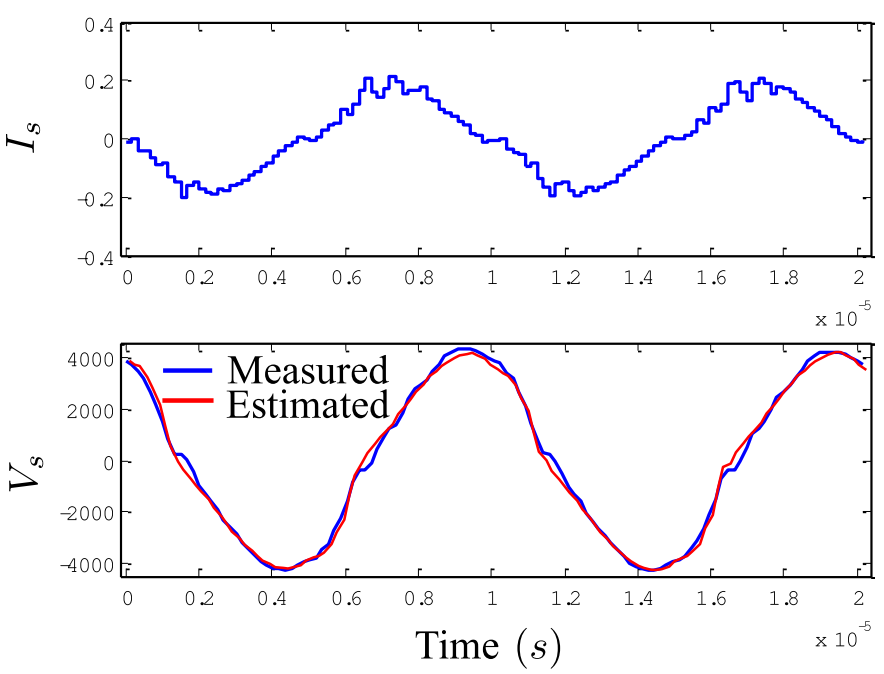

Fig. 13. Measured current $I_{S}$ and measured and estimated voltage $V_{S}$ of the DBD lamp using a resonant converter FIT $=90.1 \%$.

2) Comparison of Polynomial Terms: To simplify the model, the relative importance of each of the polynomial terms (i.e, $T_{n}\left|I_{\text {gas }}\right|$ ) is analyzed. Fig. 12 shows a comparison of the polynomial terms for the identification waveform. For this comparison the RMS value (10) is used. It can be seen that in this case the two first powers $T_{1}\left|I_{\mathrm{gas}}\right|$ and $T_{2} I_{\mathrm{gas}}^{2}$ are the

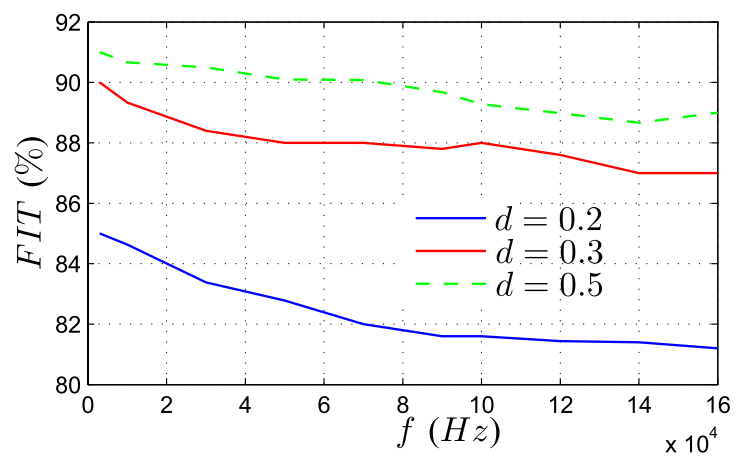

Fig. 14. FIT index for validation waveforms using the polynomial model.

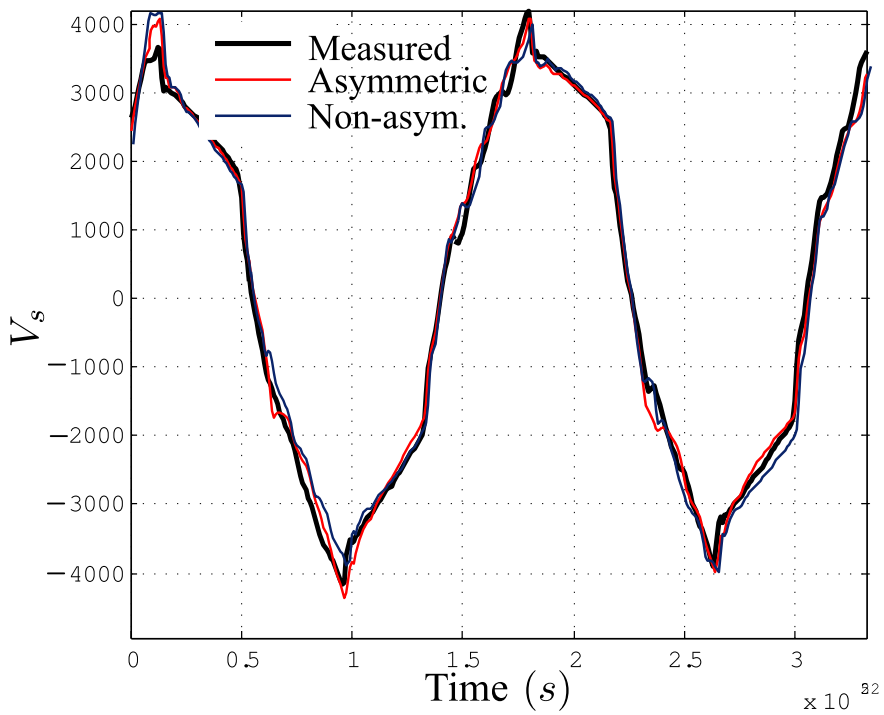

Fig. 15. Response of the identified asymmetric model $(\mathrm{FIT}=92.5 \%)$, nonasymmetric $(\mathrm{FIT}=91.7 \%)$ to the identification waveform.

most important indicating that thermal processes are involved in the discharge and approaching to the Mayr model used for low current arcs [9], [10].

3) Predictability of the Model: To test the accuracy of the identified model for different waveforms a validation process is carried out. Waveforms with different frequencies and duty cycles are used. Fig. 14 shows the obtained FIT. It can be seen that a lowest FIT is obtained for lower values of duty cycle. However, the lower value FIT $=80 \%$ still shows a satisfactory response of the model. Fig. 13 shows the response of the model to a different current $\left(I_{s}\right)$ waveform generated by a resonant converter. For this case the FIT is $90.1 \%$.

4) Identification Results (Asymmetrical Model): Table IV shows the results of the algorithm after 90 iterations (Fig. 10). The results show that for the asymmetric model the parameters vary depending on the current direction. In addition, the parameters that are independent on the conductance equation $C_{\text {gas }}$ and $C_{d}$ vary less than $5 \%$ with respect to the results of Table III.

Fig. 15 shows a comparison of the measured response of the DBD lamp and the response obtained with the asymmetric and nonasymmetric models. Again, the FIT index is used to measure the quality of the identified model. 
TABLE IV

Numerical Results of the Parameters of the Asymmetric MODEL FOR THE DBD LAMP UP TO $T_{10}$

\begin{tabular}{|l|c|c|}
\hline \multicolumn{3}{|c|}{ Parameters } \\
\hline & $I_{\text {gas }}>0$ & $I_{\text {gas }}<0$ \\
\hline$C_{d}$ & \multicolumn{2}{|c|}{$60.3 p F$} \\
$C_{g a s}$ & \multicolumn{2}{|c|}{$23.9 p F$} \\
$V_{t h}, V_{t h}^{\dagger}$ & $2004 V$ & $2420 \mathrm{~V}$ \\
$K_{1}, K_{1}^{\dagger}$ & 2128 & 3510 \\
$K_{2}, K_{2}^{\dagger}$ & 11150 & 11420 \\
$T_{1}, T_{1}^{\dagger}$ & 920.1 & 200.3 \\
$T_{2}, T_{2}^{\dagger}$ & 2200.4 & 2502.3 \\
$T_{3}, T_{3}^{\dagger}$ & 123 & 1560 \\
\hline
\end{tabular}

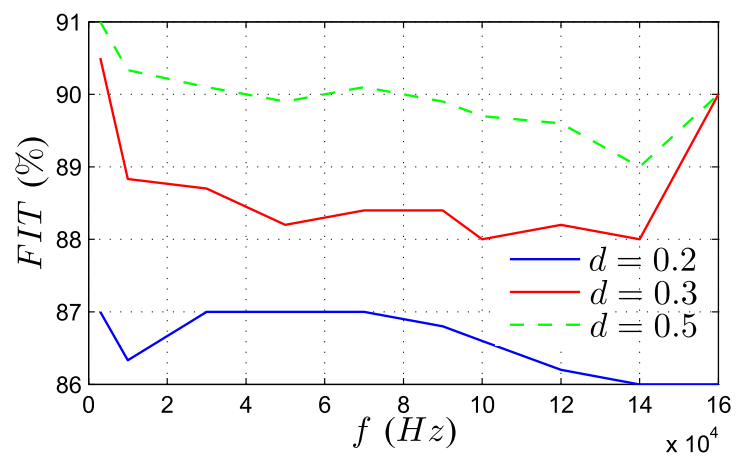

Fig. 16. FIT index for validation waveforms using the asymmetric model.
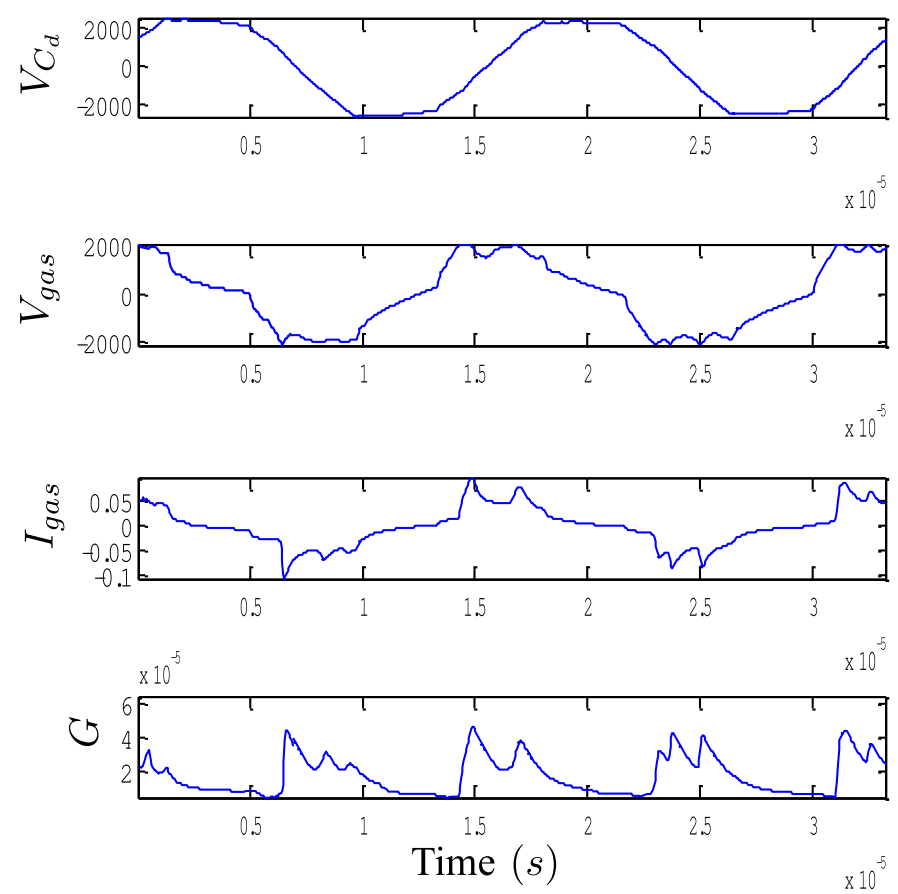

Fig. 17. Estimated variables of the DBD lamp using the identified model.

Concerning the predictability of the asymmetric model, Fig. 16 shows the values of the FIT according to various operating conditions. It can be seen that the lowest value of the FIT is $85 \%$. This is an improvement with respect to the results of Fig. 14 using the nonasymmetric model, where the lowest FIT is $80.5 \%$.
Similar to the coplanar DBD (surface treatment process), with the numerical parameters of the model and the mathematical equations, internal variables such as gas current $I_{\text {gas }}$, gas voltage $V_{\text {gas }}$, voltage of the dielectric $V_{d}$, and gas conductance $G$ can be estimated (see Fig. 17).

\section{CONClusion}

In this paper, a nonlinear identification technique for DBD systems is proposed and evaluated. This technique allows obtaining physical parameters of the lamp based on experimental measurements of current and voltage. In addition, the identified model allows estimating unmeasurable quantities such as the current of the gas.

The identification technique is tested on a DBD for film treatment and on a DBD UV lamp, obtaining very satisfactory results. On this basis the importance of each of the polynomial terms (powers of the current of the gas used to describe the gas conductance) is compared, and it is possible to carry on an analysis of the prominent phenomena, which occur in the plasma. In addition, a model that considers the asymmetry of some DBD systems such as DBD lamps is proposed and tested. This model shows an improvement in the validation results with respect to the original symmetric model.

\section{REFERENCES}

[1] U. Kogelschatz, "Dielectric-barrier discharges: Their history, discharge physics, and industrial applications," Plasma Chem. Plasma Process., vol. 23, no. 1, pp. 1-46, 2003.

[2] B. Eliasson and U. Kogelschatz, "Modeling and applications of silent discharge plasmas," IEEE Trans. Plasma Sci., vol. 19, no. 2, pp. 309-323, Apr. 1991.

[3] H. Wagner, R. Brandenburg, K. Kozlov, A. Sonnenfeld, P. Michel, and J. Behnke, "The barrier discharge: Basic properties and applications to surface treatment," Vacuum, vol. 71, no. 3, pp. 417-436, 2003.

[4] H. Piquet, R. Diez, J. Blaquière, S. Bhosle, and N. Roux, "DBD lamp converter design using an electrical model of the load," Math. Comput. Simul., vol. 81, pp. 420-432, Oct. 2010.

[5] J. Sjöberg, Q. Zhang, L. Ljung, A. Benveniste, B. Delyon, P. Glorennec, H. Hjalmarsson, and A. Juditsky, "Nonlinear black-box modeling in system identification: A unified overview," Automatica, vol. 31, no. 12, pp. 1691-1724, 1995.

[6] A. Juditsky, H. Hjalmarsson, A. Benveniste, B. Delyon, L. Ljung, J. Sjöberg, and Q. Zhang, "Nonlinear black-box models in system identification: Mathematical foundations," Automatica, vol. 31, no. 12, pp. 1725-1750, 1995.

[7] J. Castano, F. Ruiz, and J. Régnier, "A fast approximation algorithm for set-membership system identification," in Proc. 18th IFAC World Congr., vol. 18. 2011, pp. 4410-4415.

[8] R. Diez, J.-P. Salanne, H. Piquet, S. Bhosle, and G. Zissis, "Predictive model of a DBD lamp for power supply design and method for the automatic identification of its parameters," Eur. Phys. J. Appl. Phys., vol. 37, no. 3, pp. 307-313, 2007.

[9] T. Liu, K. Tseng, and D. Vilathgamuwa, "A PSPICE model for the electrical characteristics of fluorescent lamps," in Proc. 29th Annu. IEEE PESC Rec., vol. 2. May 1998, pp. 1749-1754.

[10] D. Thomas, E. Pereira, C. Christopoulos, and A. Howe, "The simulation of circuit breaker switching using a composite cassie-modified Mayr model," IEEE Trans. Power Del., vol. 10, no. 4, pp. 1829-1835, Oct. 1995.

[11] V. Tarasenko, S. Avdeev, M. Erofeev, M. Lomaev, E. Sosnin, V. Skakun, and D. Shitz, "High power VUV and UV excilamps," in Proc. IEEE ICOPS, Jun. 2009, p. 1. 
[12] M. I. Lomaev, V. S. Skakun, E. A. Sosnin, V. F. Tarasenko, D. V. Shitts, and M. V. Erofeev, "Excilamps: Efficient sources of spontaneous UV and VUV radiation," Phys.-Uspekhi, vol. 46, no. 2, p. 193, 2003.

[13] S.-H. Park, T.-S. Cho, K. Becker, and E. Kunhardt, "Capillary plasma electrode discharge as an intense and efficient source of vacuum ultraviolet radiation for plasma display," IEEE Trans. Plasma Sci., vol. 37, no. 8, pp. 1611-1614, Aug. 2009.

[14] M. Lomaev, E. Sosnin, V. Tarasenko, D. Shits, V. Skakun, M. Erofeev, and A. Lisenko, "Capacitive and barrier discharge excilamps and their applications (review)," Instrum. Experim. Tech., vol. 49, no. 5, pp. 595-616, 2006.

[15] D. W. Marquardt, "An algorithm for least-squares estimation of nonlinear parameters," J. Soc. Ind. Appl. Math., vol. 11, no. 2, pp. 431-441, 1963.

[16] J. More, "The Levenberg-Marquardt algorithm: Implementation and theory," in Numerical Analysis (Lecture Notes in Mathematics), vol. 630, G. Watson, Ed. Berlin, Germany: Springer-Verlag, 1978, pp. 105-116.

[17] T. Coleman and Y. Li, "An interior trust region approach for nonlinear minimization subject to bounds," SIAM J. Optim., vol. 6, no. 2, pp. 418-445, 1993.

[18] T. F. Coleman and Y. Li, "On the convergence of interior-reflective Newton methods for nonlinear minimization subject to bounds," Math Program., vol. 67, nos. 1-3, pp. 189-224, 1994.

[19] X. Bonnin, H. Piquet, N. Naude, N. Gherardi, and J. Blaquiere, "Alimentation électrique des dispositifs à décharge à barrière diélectrique (DBD)," in Proc. Electronique Puissance Futur, Belfort, France, 2011.

[20] D. Florez, R. Diez, K. Hay, and H. Piquet, "DBD excimer lamp power supply with fully controlled operating conditions," in Proc. 13th Int. Conf. OPTIM, May 2012, pp. 1346-1352.

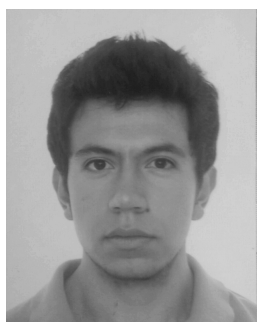

Andres Mauricio Lopez (S'11) received the B.Sc. and M.Sc. (summa cum laude) degrees in electronics engineering from Pontificia Universidad Javeriana, Bogotá, Colombia.

$\mathrm{He}$ has participated in several research projects, including a cooperation project with the University of Toulouse, Toulouse, France, and a project financed by the Administrative Department of Science, Technology and Innovation of Colombia in DBD lamps. His current research interests include switched capacitor converters and modeling and control of power converters.

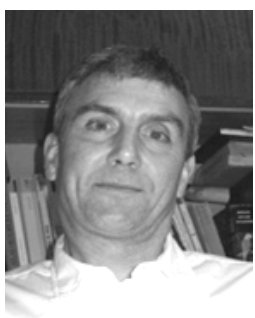

Hubert Piquet was born in Arras, France, in 1960. He graduated in applied physics from Ecole Normale Supérieure de Cachan, Cachan, France, in 1984, and the Ph.D. in electrical engineering from Institut National Polytechnique de Toulouse, Toulouse, France, in 1990.

He is currently a Full Professor with ENSEEIHT Ing. School, Toulouse. He teaches power electronics and systemic approach in electrical engineering. His research activity takes place in the LAPLACE laboratory, Energy Conversion and Plasma Laboratory, Toulouse. His current research interests include quality and stability in embedded networks as well as power supplies for plasma applications.

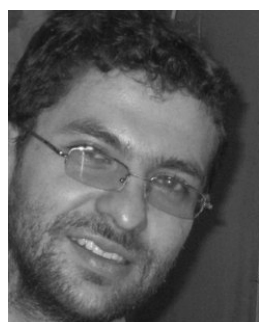

Diego Patino (M'00) was born in Manizales, Colombia. He received the B.Sc. degree in electronic engineering from Universidad Nacional de Colombia, Bogotá, Colombia, the M.Sc. degree from Universidad de Los Andes, Bogotá, and the Ph.D. degree in automatic control from Nancy University, Nancy, France.

He is currently a Full-Time Professor with Pontificia Universidad Javeriana, Bogotá. He is the author of several articles. His current research interests and nonlinear control theory. include hybrid dynamical systems, power converter,

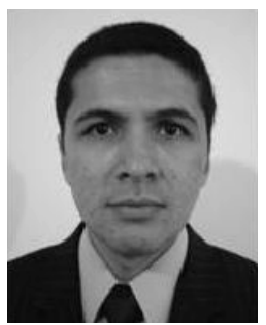

Rafael Díez (M'10) received the B.Sc. degree in electronics engineering from Pontificia Universidad Javeriana, Bogotá, Colombia, in 2001, and the M.Sc. degree in microelectronics, and the Ph.D. degree in electrical engineering from Université de Toulouse, Toulouse, France, in 2005 and 2008, respectively.

$\mathrm{He}$ is currently with the Department of Electronics, Pontificia Universidad Javeriana. His current research interests include the development of power converters for electric discharges.

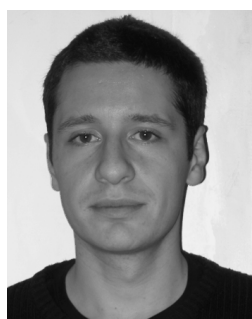

Xavier Bonnin was born in Clermont-Ferrand, France, in 1985. He received the M.S. degree in electrical engineering from École Normale Supérieure de Cachan, Cachan, France, in 2011. He is currently working on his Ph.D. thesis with the LAPLACE laboratory.

His work concerns both the study of the coupling between electrical power sources and plasma devices and the methodologies in designing power electronics components for plasma applications. 